among the truly predominant e-prescribers.

Second, the findings by Ross et al. are restricted to 2 intermediate outcome measures: the ratios of formulary prescription claims and generic drugs to total pharmacy claims. Possible administrative efficiency in the form of fewer calls between prescribers and pharmacies was not measured quantitatively but noted as a qualitative finding from a survey of some prescribers. There is also the administrative efficiency for the pharmacy in the entry of keystrokes by prescribers rather than pharmacy staff for prescription orders. But, others have observed from the current environment of e-prescribing that small independent pharmacies are slow to upgrade their pharmacy management systems to accept e-prescriptions because of large fees charged by software vendors; large chain pharmacies embrace e-prescribing at the corporate level, but local store support is low and there is inadequate training of pharmacy staff. ${ }^{13}$

Physician resistance to change, system cost, and inadequate planning to incorporate e-prescribing into the existing care process have been blamed for failures in introducing e-prescribing in health systems. ${ }^{4}$ The Centers for Medicare and Medicaid Services (CMS) acknowledged the receipt of about 100 comments in response to the CMS proposal in early February 2005 for e-prescribing standards to take effect prior to the start of the Medicare Part D benefit on January 1, 2006. William Jesse, CEO of the Medical Group Management Association (MGMA), wrote in his letter to CMS Administrator Mark McClellan that the MGMA contends that the benefits of e-prescribing compared with its costs are "simply not evident." The letter also called for CMS to "establish a quantifiable return on investment through survey research and a comprehensive cost-benefit analysis for all sizes of physician practices." ${ }^{14}$ The American Medical Association has been critical of the political agenda to mandate e-prescribing by physicians. ${ }^{15}$

Modern Healthcare's 14th annual survey of information systems needs conducted in January 2004 found that 24\% of surveyed organizations had a CPOE system either in operation or implementation, about the same number as the year before, in January 2003. Unlike 2003, however, in which $40 \%$ of those without a CPOE system in operation or implementation reported that they planned to add a CPOE system within the next year, in January 2004, only 26\% expected to do so in the next year. ${ }^{16}$

Data from the National Health Care Survey, Centers for Disease Control and Prevention, suggest a less pronounced dissemination of information technology for office-based physicians. In 2003, only $7.9 \%$ of office-based physicians used CPOE, 17.2\% had electronic medical records (EMR), and $73.2 \%$ used electronic billing for their-party claims. ${ }^{17}$ The CDC data support the Modern Healthcare survey data in the more widespread use of information technology in hospitals with $31 \%$ of emergency departments and 29\% of hospital outpatient centers reporting use of EMR.
Amid the pushback from some physicians and the apparent waning interest of health systems in e-prescribing, there is evidence of improved cost outcomes and efficiency in the use of e-prescribing. In the May 2005 issue of JMCP, McMullin et al. found that e-prescribing that included a clinical decision support system (CDSS) was associated with significant drug cost savings and reduction in the proportion of high-cost drugs in 8 therapeutic categories that were the target of CDSS messages to prescribers. ${ }^{18}$ Over 12 months of follow-up, the average cost per prescription was reduced by $\$ 2.57$ (5.3\%), and PMPM drug cost was reduced by $\$ 1.07(5.4 \%)$ in the e-prescribing group compared with the control group. Average drug cost savings of $\$ 863$ to $\$ 873$ per prescriber per month overwhelmed the administrative cost of the e-prescribing system. Targeted highcost drugs in the 8 therapeutic categories were $17.5 \%$ lower in the intervention group (35.8\%) compared with the control group (43.4\%, $P=0.03)$.

So, an e-prescribing system with CDSS can influence prescribing and produce drug cost savings. While important to health systems at risk for pharmacy benefit costs, another factor seems to guarantee that e-prescribing will increase in frequency and soon overtake traditional prescribing, perhaps due to factors other than evidence that e-prescribing can be used to reduce direct drug costs. In the last year, Blackberry and other wireless communication devices have been breaking down barriers of resistance to change. The ubiquitous and loweffort features of this technology will transfer to clinician prescribing, and rather than resisting e-prescribing, clinicians will be demanding it. Yet, it will remain necessary to spend money on new and upgraded system software to integrate e-prescribing with the electronic medical record to overcome electronic silos of data that reside in pharmacies, at pharmacy benefit managers, or in data warehouses and are not available to clinicians at the point of care.

What will shorten the timeline between the reality of today and the inevitability of tomorrow is studious examination of the work of pioneers in adapting and implementing IT solutions in health care settings. Among the many sources of this information is a compilation by GroupPOE, created in October 2002, entitled "Landmines and Pitfalls of Computerized Prescriber Order Entry." ${ }^{19}$ While nearly 3 years old, the recommendations and lessons contained in this document are still relevant and useful today.

\section{Best Value for Money in Triptans}

In this issue of JMCP, Mullins et al. rely principally upon the previously published meta-analysis by Ferrari et al. ${ }^{20}$ to estimate the doses needed to treat (DNT) for a successful clinical outcome in 100 patients. ${ }^{21}$ Mullins et al. define success in their model as 2-hour pain response, sustained through 24 hours postdose, for patients who experience a migraine episode.

The original article by Ferrari et al. that described their 
results of meta-analysis of 53 clinical trials was published in The Lancet in 2001.22 That article triggered a vigorous response, including letters to the editor, providing a rich source of insight into the methods used in meta-analysis, in general, and specifically as employed by Ferrari et al. in evaluation of the relative efficacy of the triptans. Dowson and Kilminster ${ }^{23}$ and Kernick ${ }^{24}$ found little relevance to clinical practice in the work by Ferrari et al. Tfelt-Hansen argued that Ferrari and colleagues were misleading in reporting that they had calculated all of the parameters for all patients when, in fact, he had supplied the data for a sumatriptan clinical trial that were not "real raw clinical data" but summary counts of patients in each treatment group and the number of patients with sustained pain-free response, as determined by the study investigators. ${ }^{25} \mathrm{He}$ also criticized the selective use of data including the disregard of head-to-head clinical trial data that found no difference in efficacy between $100 \mathrm{mg}$ sumatriptan and $12.5 \mathrm{mg}$ of almotriptan and in a large clinical trial of 1,173 patients in which there was $25 \%$ pain-free response with $50 \mathrm{mg}$ sumatriptan compared with $18 \%$ pain-free response with $12.5 \mathrm{mg}$ almotriptan $(P=0.005)$; at 2 hours, almotriptan treatment provided headache relief in $58.0 \%$ of the subjects and sumatriptan treatment in $57.3 \% .{ }^{26}$ Cates alleged that Ferrari et al. did not address adequately the high placebo response rates found in some of the almotriptan trials. ${ }^{27}$ Ferrari et al. responded to these letters, including the notation that only placebocontrolled trials were included, thereby precluding the use of head-to-head clinical trials in the meta-analysis. ${ }^{28}$

There is a robust and large literature on the methodological issues surrounding the determination of relative efficacy of the triptans for acute migraine. In their analysis of 51 published clinical trials of triptans for acute migraine, Fox et al. concluded that while the distribution of active drug response rates passed a chi-squared goodness-of-fit test, consistent with a normal distribution, the placebo response rates were not normally distributed, and the distribution of therapeutic gains failed a test of normality $(P=0.018)$, as did the numbers needed to treat (NNTs) $P<0.001) .{ }^{29}$ Therefore, the choice of transformation of distributions of active and placebo response rates into therapeutic gains, NNTs and therapeutic ratios is a potential source of bias in meta-analysis of acute migraine therapies.

Systematic reviews and meta-analyses are based on the quality of the primary articles and clinical trials. Moja et al. found that systematic reviews often failed to evaluate the methodological quality of the primary clinical trials that were the basis of the systematic review, ${ }^{30}$ and Hewitt et al. found that despite the CONSORT statement (in which researchers must include a short checklist of essential items and a flow diagram when reporting clinical trial ${ }^{31}$ ), more than $40 \%$ of trials published in 4 major medical journals (British Medical Journal, JAMA, The Lancet, and the New England Journal of Medicine) published from January 2002 to December 2002 either did not use adequate methods (18\%) or failed to describe how they concealed the allocation of subjects (26\%). ${ }^{32}$ Since studies that use inadequate allocation concealment are more likely to report significant findings than those using adequate concealment, it is necessary to critically assess the reported methods of allocation concealment. However, $44 \%$ to $93 \%$ of published articles of results of randomized controlled trials (RCTs) have been found to lack a clear description of allocation concealment. . $33,34^{3}$

DNTs and NNTs are potentially valuable measures of efficiency when combined with real-world drug cost data. In this way, it is possible to estimate the drug cost per successful outcome. Mullins et al. used the best available efficacy data for the triptans and a reasonable estimate of drug cost for a typical managed care organization ([MCO] absent manufacturer price discounts and rebates), calculated as $85 \%$ of average wholesale price (AWP), to determine the triptan drug cost necessary to treat 100 patients. Thereby, Mullins et al. increases our knowledge of methods to determine the relative value for money of triptans.

This incremental knowledge is imperfect, however, for at least 2 reasons. When making drug formulary decisions, it is also necessary to examine the actual MCO drug cost data and utilization of the alternative products. For example, drug formularies typically do not specify coverage or preferred status for one strength of drug over another, such as almotriptan $12.5 \mathrm{mg}$ but not almotriptan $6.25 \mathrm{mg}$ tablets. Therefore, most Pharmacy \& Terapeutics committees would examine the actual MCO average charge (allowed drug cost + dispensing fee) per pharmacy claim and per day of triptan therapy. Data for the first 90 days of calendar year 2005 from a pharmacy benefit manager (PBM) database of small employers showed an average charge per day of $\$ 13.55$ and $\$ 189$ per claim for eletriptan, before rebate, lower actual incurred cost per day and per pharmacy claim than all 6 of the other triptans: $\$ 13.55$ per day for eletriptan, $\$ 14.05$ for naratriptan, $\$ 14.08$ for almotriptan, \$14.98 for zolmitriptan, $\$ 15.36$ for rizatriptan MLT, $\$ 15.42$ for frovatriptan, $\$ 16.28$ for sumatriptan, $\$ 16.49$ for rizatriptan, $\$ 18.35$ for zolmitriptan ZMT. ${ }^{35}$ It is probably comforting to most managed care pharmacists that the evaluation by Mullins et al. advocates the use of a drug that is not only cost effective but also lower in actual drug cost per pharmacy claim.

Second, it is noteworthy that Mullins et al. concluded that eletriptan $40 \mathrm{mg}$ had the lowest NNT, the lowest DNT, and the lowest total triptan cost $(\$ 5,630)$ to successfully treat 100 patients ( $\$ 56.30$ per successfully treated patient), while Ferrari et al. concluded that rizatriptan $10 \mathrm{mg}$, almotriptan $12.5 \mathrm{mg}$, and eletriptan $80 \mathrm{mg}$ offer the highest likelihood of consistent success in relief of migraine episodes. Alas, eletriptan is available in the United States in only the $20 \mathrm{mg}$ and $40 \mathrm{mg}$ doses, and the maximum dose in product labeling for eletriptan is $40 \mathrm{mg}$ because, while the $80 \mathrm{mg}$ is effective, it is "associated with an increased incidence of adverse events." appear to be additional opportunity to learn more about the 
optimum value for money in the use of triptans. Ferrari et al. provide a guidepost to other researchers in their abstract from the meta-analysis of triptan randomized controlled trials published in 2002: "The major methodological issues involve the choice of primary end point, consistency over multiple attacks, how to evaluate headache recurrence, use of placebosubtracted proportions to control for across-study differences, and the difference between tolerability and safety."20

\section{Frederic R. Curtiss, PhD, RPh, CEBS}

Editor-in-Chief fcurtiss@amcp.org

\section{REFERENCES}

1. de Kare-Silver N. Choose and book-whose choice is it anyway? BMJ. 2005;330:1093. Available at: http://bmj.bmjjournals.com/cgi/content/ full/330/7499/1093. Accessed May 10, 2005

2. MacKenzie GM. Are choose and book and NPiT such an advance? BMJ. May 9, 2005; Rapid Response. Available at: http://bmj.bmjjournals.com/cgi/ eletters/330/7499/1093\#106237. Accessed May 15, 2005.

3. Fernando B, Savelyich BS, Avery AJ, et al. Prescribing safety features of general practice computer systems: evaluation using simulated test cases. BMJ. 2004;328:1171-72.

4. Morrissey J. Harmonic divergence-Cedars-Sinai joins others in holding off on CPOE. Mod Healthcare. February 23, 2004:16.

5. Curtiss FR. Clinical, service, and cost outcomes of computerized prescription order entry. J Manag Care Pharm. 2005;11(4):353:55.

6. Amalberti R, Auroy Y, Berwick D, Barach P. Five system barriers to achieving ultrasafe health care. Ann Intern Med. 2005;142(9):756-64.

7. James BJ. Quality improvement opportunities in health care-making it easy to do it right. J Manag Care Pharm. 2002;8(5):394-99.

8. Kelly Schuerenberg B. An Rx for reducing medication errors. Health Data Manage. May 2005:68-76.

9. Martinez B. Employers group to unveil plan to reduce medical errors. Wall Street Journal. January 17, 2002:B2.

10. Simou A. Newt: An intelligent health system for the 21 st century. February 10, 2005. Available at: http://www.newt.org/index.php?src= news\&prid $=954 \&$ category $=$ Articles \&noframe $=y$. Accessed May 14, 2005

11. Versel N. Big Three auto makers lobby 17,000 docs to e-prescribe. Health IT World. April 26, 2005. Available at: http://www.health-itworld.com/enews/ 04-26-2005_576.html. Accessed May 15, 2005.

12. Ross SM, Papshev D, Murphy EL, Sternberg, DJ, Taylor J, Barg R. Effects of electronic prescribing on formulary compliance and generic drug utilization in the ambulatory care setting: a retrospective analysis of administrative claims data. J Manag Care Pharm. 2005;11(5):410-15.

13. Tcimpidis L, Rosenblatt M. Readers' perspectives. Health Data Manage. May 2005:88.

14. Conn J. Rx for e-prescribing—groups offer comments on proposed standards. Mod Healthcare. April 18, 2005:33.

15. Anonymous. Electronic prescribing and Medicare: let the doctor decide [editorial]. Amednews.com. November 3, 2003. Available at: http://www.amaassn.org/amednews/2003/11/03/edsal103.htm Accessed May 7, 2005.

16. Morrissey J. Capital crunch eats away at IT. Mod Healthcare. February 23, 2004:32.

17. Anonymous. By the numbers. Mod Healthcare. May 2, 2005:9.

18. McMullin ST, Lonergan TP, Rynearson CS. 12-month drug cost savings related to use of an electronic prescribing system with integrated decision support in primary care. J Manag Care Pharm. 2005;11(4):322-32.

19. Clark T, for GroupPOE. Landmines and pitfalls of computerized prescriber order entry. Available at: http://www.ismp.org/PDF/ LandminesandPitfallsofCPOE.pdf. Accessed May 15, 2005.
20. Ferrari MD, Goadsby PJ, Roon KI, et al. Triptans (serotonin, 5-HTlB/1D agonists) in migraine: detailed results and methods of a meta-analysis of 53 trials. Cephalalgia. 2002;22:633-58.

21. Mullins, CD, Weis KA, Perfetto EM, Subedi P, Healey PJ. Triptans for migraine therapy: a comparison based on number needed to treat and doses needed to treat. J Manag Care Pharm. 2005;11(5):394-402.

22. Ferrari MD, Roon KI, Lipton RB, et al. Oral triptans (serotonin 5HTIB/1D agonists) in acute migraine treatment: a meta-analysis of 53 trials. Lancet. 2001;358:1668-75.

23. Dowson A, Kilminster S. Triptan medications to treat acute migraine [letter]. Lancet. 2002;359:1151-52. Available at: http://www.thelancet.com/ journals/lancet/article/PIIS0140673602081308/fulltext. Accessed April 30, 2005.

24. Kernick DP. Triptan medications to treat acute migraine [letter]. Lancet. 2002;359:1152. Available at: http://www.thelancet.com/journals/lancet/article/ PIIS0140673602081321/fulltext. Accessed April 30, 2005.

25. Tfelt-Hansen P. Triptan medications to treat acute migraine [letter]. Lancet. 2002;359:1152. Available at: http://www.thelancet.com/journals/lancet/ article/PIIS014067360208131X/fulltext\#bib2. Accessed April 30, 2005. 26. Spierings EL, Gomez-Mancilla B, Grosz DE, et al. Oral almotriptan vs. oral sumatriptan in the abortive treatment of migraine: a double-blind, randomized, parallel-group, optimum-dose comparison. Arch Neurol. 2001;58(6): 944-50. Available at: http://www.thelancet.com/journals/lancet/medline/record/ MDLN.11405809. Accessed April 30, 2005.

27. Cates C. Triptan medications to treat acute migraine [letter]. Lancet. 2002;359:1152. Available at: http://www.thelancet.com/journals/lancet/ article/PIIS0140673602081333/fulltext. Accessed April 30, 2005.

28. Ferrari MD, Roon KI, Lipton RB, Goadsby PJ. Triptan medications to treat acute migraine. (letter). Lancet. 2002; 359:1152-53. Available at: http://www.thelancet.com/journals/lancet/article/PIIS0140673602081345/ fulltext. Accessed April 30, 2005.

29. Fox AW, Keywood C, Sheftell FD, Spierings EL. Consequences of transforming measures of efficacy for acute therapies: 5-HT agonists as a worked example. Headache. 2004;44(1):48-52.

30. Moja LP, Telaro E, D'Amico R, et al. Assessment of methodological quality of primary studies by systematic reviews: results of the metaquality crosssectional study. BMJ. 2005;330:1053-55.

31. Altman DG, Schulz KF, Moher D, et al. The revised CONSORT statement for reporting randomized trials: explanation and elaboration. Ann Intern Med. 2001;134(8):663-94.

32. Hewitt C, Hahn S, Torgerson DJ, et al. Adequacy and reporting of allocation concealment: review of recent trials published in four general medical journals. BMJ. 2005;330:1057-58.

33. Jüni P, Altman DG, Egger M. Systematic reviews in health care: assessing the quality of controlled clinical trials. BMJ. 2001;323:42-46.

34. Pildal J, Chan A, Hróbjartsson A, et al. Comparison of descriptions of allocation concealment in trial protocols and the published reports: cohort study. BMJ. 2005;330:1049-52.

35. Data abstracted April 3, 2005, from a national pharmacy benefits manager (PBM) data warehouse representing approximately 500,000 beneficiaries of small employer drug benefit plans with dates of service from January 1, 2005, through March 31, 2005.

36. Drug Facts and Comparisons (CliniSphere 2.0). April 2005. St. Louis, MO: Wolters, Kluwer Health, Inc. Central nervous system agents, agents for migraine, serotonin 5-HT 1 receptor agonists, eletriptan HBr. Accessed May 15, 2005.

\section{Letters to the Editor}

JMCP welcomes letters that serve to clarify subjects published in previous issues of the Journal or regarding subject matter of interest to managed care pharmacists. Letters in JMCP are not peer reviewed but are subjected to editorial review. Letters should be prepared in a word processing program, preferably Microsoft Word, and submitted electronically at jmcp.msubmit.net. See www.amcp.org for details. 